\title{
5. Engaging Citizens in Policy Innovation: Benefiting public policy from the design inputs of citizens and stakeholders as 'experts'
}

\author{
Christian Bason
}

In this chapter I will clarify various ways of engaging with citizens and involving them in the processes of policy-making. I would also like to encourage us, as policy actors, to be more conscious about using citizen engagement to reorient what we do to better meet citizens' expectations as well as capture the benefits from inputs of other important actors and stakeholders. The perspective I bring to this contribution is to ask: how can we really engage citizens to drive innovation in policies and services, and help us to produce better outcomes.

As an important backdrop to our discussion, we need to be aware of the financial crisis affecting governments around the globe. It's a 'perfect storm' involving a toxic mix of financial pressures that are driven by multiple winds of change, with the impacts stemming from demographic change, and from the rising cost of new technologies. Governments are still expected to solve tough social issues and deliver services in this context, while meeting the rising expectations of citizens over the quality of delivery. So, for instance, with demographic changes and ageing we are seeing particular sectors, like the healthcare sector and the social services sector, undergoing massive pressures and transformations across the Organisation for Economic Co-operation and Development (OECD) countries.

\section{Improving meals at the Hvidovre hospital}

Let me begin by highlighting what citizen-centric innovation can really mean with an example from the Danish health sector, where a hospital produced significant innovations to the patient experience. At the Hvidovre hospital - a major hospital serving the Copenhagen region - the hospital kitchen serves both the hospital staff and the patients. A few years back, the head chef, Michael Allerup, was irritated because he could see that much of the food his kitchen was producing ended up in waste containers, situated right outside the kitchen window. Patients were not eating what he was producing, there was massive waste and, as a professional chef, this left him dissatisfied. 
To deal with the situation, he sought expert help and invited a private sector gourmet chef, Rasmus Bo Bojesen, to offer professional advice. Bojesen was well known for his pastry and ability to deliver excellent food to large groups of people in a professional way. And so began an innovative collaboration between the private sector gourmet chef and the hospital chef. Bojeson began by checking in to the hospital personally, posing as a patient, in a hospital bed, so as to experience for himself what patients experienced every day in terms of the food service. He reviewed the service as a citizen who was knowledgeable about food.

What he saw were poorly presented meals, served at the convenience of management. He realised that the food itself probably wasn't that bad, but it did not look appetising or attractive. He also realised that, the hospital kitchen's service of meals at fixed times of the day, with the same size portions, did not necessarily fit with what patients felt like eating, particularly after an operation, or when they were awake at strange hours of the day.

In short, he experienced for himself the challenges inherent in the existing meal service, and came up with a number of potential solutions, in collaboration with the hospital chef. They introduced a restaurant style menu that allowed clients to select what they wanted, introduced smaller meals for people with limited appetites, due either to age or health, and they used organic and fresh food, and made sure that patients could order meals at any time of the day.

Now, the food at the Hvidovre hospital is inviting and appetising. Of course it's wonderful to be able to prepare better food, and provide the catering service in a way that is tailored to the needs of individual. Certainly, the 'service experience' for patients was dramatically improved, but, more interestingly, under the new arrangements the production of the hospital's food cost 30 per cent less than before, mainly because of less food waste. By catering on and to demand, patients eat the good food that the kitchen produces according to requirements.

That, however, wasn't end of the innovation. Bojesen thought to himself: 'well, we're in a hospital, and I'm wondering whether this food is not also making people more healthy?' In response, he began another process of collaboration with one of the resident doctors to measure whether the better quality food had any impact on patient recovery and the average length of stay at the hospital, and it turned out that it did. It reduced the average amount of stay by approximately one full day. As one would imagine, to be able to make such an average reduction in the length of stay represents a massive saving for the hospital.

This story illustrates some of the value that can come from redesigning services or policies around the citizen experience. In the case of Hvidovre hospital, 
productivity was increased by savings in catering costs and the reduction in the length of hospital stays; there was a better service experience for citizens, which is what the public expects from a hospital in a wealthy country like Denmark; and, there were also better outcomes in terms of improving health. Clearly, even relatively simple innovations can lead to harvesting benefits in the longer term - a win-win-win situation.

This project was not primarily motivated by notions of democratic participation, or by the agenda of 'patient rights', but simply by redesigning services to suit client needs. The project produced multiple types of value and impacted on multiple bottom lines. This is the real challenge of public sector innovation: to add value across multiple dimensions - not just productivity, but also the service experience - as well as in measurable outcomes. And the interesting point is that, if we start from the citizen's perspective and understand how they experience what we're doing to or for them, these can become the triggers by which we can start to contemplate the generation of value across multiple dimensions.

So, in considering these ideas of citizen-centric governance, citizen-centred innovation, or user-driven innovation, and all the other ways of expressing such initiatives, there seems to be a consensus around the globe that we know there is real value to harvest, and we can produce new value by engaging citizens in new ways. This raises the questions, then, of how do we do it, and what are the best ways of achieving it? These are the two questions I want to explore in the remainder of this chapter.

\section{Incubating innovation: Denmark's MindLab venture}

The agency I lead, MindLab, is focused on these questions while concentrating exclusively on the public sector. MindLab is an active collaboration between three Danish government ministries, businesses and citizens aimed at the cocreation of new public policy and public services. ${ }^{1}$ We think of ourselves as a 'citizen-centred innovation' in our own right. MindLab, which has existed for close to 10 years, was originally established by a senior executive of the business ministry, and sponsored by the permanent secretary at that time. When I joined about five years ago, we redesigned and expanded MindLab, adding a research dimension and embedding MindLab in the top management of government.

1 MindLab is part of the ministry of business and growth, the ministry of taxation and the ministry of employment. The story of MindLab has been recorded in an online article in the monthly newsletter, Monocle (see 'North Stars', 44, June 2011, pp. 121-24). My recent book, Leading Public Sector Innovation: Co-creating for a better society (Polity Press, London, 2010), expands on many of the points raised here. 
Over the years, MindLab has shifted from its early orientation around the laboratory idea - using a physical space to be creative, to discover, innovate and experiment - to being more about facilitating citizen-centric innovation, more research-oriented, and more about cross-cutting policy issues involving our departments, other levels of government (such as local municipalities) and the community. Our three departments of business and growth, employment, and taxation, share a lot of common policy challenges around, for example, administrative burdens, and engaging with citizens when it makes sense to involve them.

At MindLab we have a specialised staff of 15, consisting of anthropologists, designers, ethnographers, and a few people from the public sector or with a public servant background. We are located within the ministry of business and growth, in a physical space that serves as a platform for collaboration, where public servants work together with us, and with citizens and experts, in a co-creative fashion. We see our role being not to come up with bright ideas on behalf of our colleagues, who are public servants like us, but, instead, we facilitate processes and support and help them to create their own better ideas.

The key point I want to make about citizen-centred innovation and involving citizens in better policy design is the importance of finding better ideas that will have a chance of working for the users, and for the policy providers who usually want to invest their time and efforts in policies that work in practice. Being citizen-focused also means that we need to involve public and private sector employees who are not only a good source of ideas, but who will be responsible mainly for overseeing implementation. When we start new projects we ask our colleagues: is this something that you hope will work, or are you just doing it to satisfy the minister or media, or simply to say that you've done it? We , say if you want to do something that works for people, then you probably need to think about involving them from the outset.

\section{Co-creation of policy through 'professional empathy'}

The concept I call 'co-creation' represents a particular take on involving citizens from the start. It's a broad involvement and a holistic one, addressing the question of how we fit citizen engagement into all the dialogues and deliberations we have when we craft new policies. My argument would be that we have to locate the citizens' own reality more centrally in our policy processes, together with our knowledge about citizen expectations and behaviours - in short, we have to capture the citizens' lives. The main message I wish to convey is that we need to get closer to citizens' lives to understand how they do things, to then be able 
to radically redesign our services. Of course, many other things will be going on in such policy processes - information gathering, costing and consultations, for example, and I am not saying we should replace or abandon everything that we usually do. But, we should add co-creation as something that is important and, potentially, helpful.

I will make three points about co-creation, and this is the essence of the remainder of my chapter. First of all, we need to be involving a wider variety of people in policy design - and I will return to what I mean by that shortly. Second, we need to understand more specifically how people live their lives, what their real experiences are in concrete and qualitative ways - this is a new mode of knowledge that I call 'professional empathy'. And, finally, we should use or orchestrate different kinds of policy creation, or 'service creation processes', inspired by what the best designers do and how designers work in practice.

Encompassing a broader scope of people is about involving more people sooner, early in the policy or service development phase, and about public organisations doing it consciously.

To give a second example, when we were asked to orchestrate a policy process exploring clean environmental technologies and involving six different Danish government departments, including climate change, energy, environment and foreign affairs, we invited the famous Danish-Icelandic artist, Olafur Eliasson, who had done a lot of work about climate change with private companies like BMW, to give a presentation to this group of about 20 senior public servants. Some selected private businesses that were at the forefront of clean technologies, and at the forefront of developing new solutions to climate change, were also invited to attend Eliasson's presentation. The intention was to bring together these different officials from different departments with other types of actors such as artists, business representatives and citizens to gain a common understanding of the multiple challenges we faced. We wanted to facilitate a process of understanding to enable us to craft a business strategy that could both help build Danish commercial success in the field of clean technology and also address climate change.

When Eliasson spoke to this group at a workshop at MindLab, the artist said something along the lines that: 'you know what art can bring to the policy process is a focus on precision, about actually being elitist and very precise about how you want to develop policies; it's about relationships between what you develop as an artist and the observer or the user'. In the case of Eliasson's own artwork, such as his famous artificial sun exhibited at the Tate Modern gallery in London, he is concerned with the interactions with his end users, and this was the key point that the officials took from his presentation. It became a common point of reference across the various silos of government, and it 
inspired the officials who would be responsible for the process of developing a profitable clean technology sector. The learning experience came about because we chose to involve a wider variety of people in the deliberative process - even unlikely candidates such as, in this case, an artist.

So, most importantly, 'people' are both citizens and end users, but they are certainly also system actors. Often, when we craft new policy services, we don't involve even our own work colleagues as much as we should, or we do it too late for them to understand what's going on or for them to make a meaningful contribution. What I am arguing here is that we should think explicitly about who needs to be involved to bring knowledge and inspiration, and insightful contributions to bear on the process. And, of course, that could potentially be a wide variety of actors, who may not themselves see the connection. The art of the policy facilitator is to find ways of achieving involvement through workshops, interviews, and various types of collaboration that are meaningful to the participants and helpful to the process.

It is true that some of our co-design methods may not suit every citizen, each of whom has different levels of personal capacity. At MindLab we reach citizens or businesses in many different ways, but the important part is to make a strategic selection, and make a reasonable and informed choice about who we want to engage with and how we want to engage with them. Usually we are engaged in onsite fieldwork, which involves going into people's homes or their businesses. We try to capture the range of experiences people have with existing services. Also, to establish a clear picture, we use what we call 'cultural probing', in which we provide people with materials, notebooks, or cameras so that they can document their daily lives or practices and, in doing so, become our informants in a more active way. More formally, we invite participants from different backgrounds and competencies to our workshops and conversations.

You might say, however, that this sounds like a lot of unnecessary work and, of course, it is extra work. But it is all about qualifying policy and gaining inspiration, gaining knowledge from experiences, trying to broker a common understanding of what the problem really is that you are attempting to address. And I would say the crucial task for managers is to orchestrate the process in ways where we don't involve everyone all the time, but we do it in ways that are meaningful and sensible. The key point I want to make here is that end user citizens and businesses need to be at the heart of that process, while others can make valuable contributions too.

This new mode of policy knowledge, the so-called 'professional empathy', is about the systematic ability for a public organisation, or any organisation, to experience what citizens experience, just as the gourmet chef Bojesen did at the Hvidovre hospital, jumping into the hospital bed and experiencing for himself 
what it felt like personally to receive the food service. And, of course, there are many ways of involving citizens. We can involve citizens in understanding the present or the past through quantitative surveys, or through more qualitative research; we can also engage with citizens to craft a new future. And we need to do both in order to anchor our innovation efforts in citizens' experience and in reality.

\section{Focusing on qualitative citizen engagement in policy creation processes}

Usually, when policy-makers seek input from citizens in policy processes they spend most of their time on quantitative metrics and surveys. These are valuable inputs oriented towards the responsive-end of the policy spectrum, telling us about citizen reactions, but they don't tell us anything about what to change. They may tell us something about how big the problem is, but not specifically what needs to be changed to alleviate the problem. So we need to go much deeper and move more toward qualitative inputs in order to drive innovation. Accordingly, at MindLab we concentrate on the qualitative ways of understanding citizens' experiences - trying to get to the designer-end of the spectrum and exploring other types of engagement. In running designdriven workshops, we are seeking ways to co-create policy from the outset that will involve quality delivery through co-operation and mutual forms of collaboration.

A few further examples will illustrate the point of getting up close and qualitative with citizens. In Denmark, we have come a long way in understanding administrative burdens on businesses - burdens that waste time and place additional costs on business. The government has pledged to reduce such administrative burdens as part of creating a pro-business, proinnovation environment. Rules, regulations and government requirements have to be experienced as sensible and meaningful to business, otherwise they are counterproductive. To highlight such dilemmas, we often send colleagues into the field with video cameras to record the experiences of stakeholders, and show what it feels like to be on the receiving-end of government bureaucracy and red tape. To this end, we have filmed Danish farmers trying to negotiate their way through the Danish bureaucracy and its complicated administrative burdens. When filming and interviewing, we try to understand what the triggers are that irritate or annoy, or seem meaningless to business, and we try to understand how they feel as actors within the system.

Another example would be when we questioned citizens who had serious work injuries about what it felt like to be receiving the service package from 
the Danish board of industrial injuries - a public agency intent on being an efficient case manager. We conducted in-depth, qualitative interviews with only a few citizens, but, significantly, we stayed with these citizens in their homes to feel what it was really like to be treated as an injured worker by the system. In their homes they could show us all the files, the 25 different letters, all the processing and insurance papers they had accumulated, and all of the complicated administrative work that goes into settling a work injury case. And what we found when we examined their unfortunate experiences through their own eyes, was that the way the system works often makes people more sick than they are already. This insight was fundamental for the operations of the industrial injury agency. It took the findings seriously, and began working in many different ways to make the outcome of undergoing a work injury case a more meaningful and positive experience for the citizen.

Obviously, staff working for the agency did not go to work every day trying to make people more sick - and, in fact, many hope that they are doing a good job - but our qualitative research exposed many problems in the system and showed that the agency has the potential to significantly better its performance so as to improve the experience for those injured. The agency is now trying to redesign its policies around the citizen experience, and is trying to leverage the funding mechanisms - including the private insurers - to invest more in the citizens' abilities, helping them get back on their feet, paying off their mortgages and ultimately finding a job again. Being creative is also about rethinking funding incentives and opportunities to use resources differently to enhance outcomes.

Another case in which MindLab qualitatively studied citizens' experiences was when we explored why young Danish citizens do not use online digital tax services. The Danish tax ministry reported statistics that showed the age group in Denmark that was least likely to use online digital tax services were people under 30. The ministry could produce the figures and the statistics, but they did not understand why the most digitally aware generation in Denmark were not using the services. So, we interviewed Dennis, a 23-year-old apprentice who had just got his first job. We asked him why he, and young citizens like him, did not use online processing for his tax affairs. And, in the course of our interview, we discovered that of course Dennis has a computer, uses it, and even has broadband. But he does not 'get the tax language', and nor does he understand the logic of the site developed by the tax ministry. For example, he is uncertain of the process required of him to alert the system when he receives a higher salary from his emplyer. To him therefore, it makes more sense to get in his car and drive the 23 kilometres to the local municipal office where he can have his tax affairs done manually by the nice staff member there. This is costly and contrary to the digitisation efforts of the tax ministry. 
We explored what it would take to get Dennis to be able to complete a transaction online. We began by observing how he used a computer and what understanding he had of the online sites he visited. Armed with this information, the tax ministry is now beginning a major re-conceptualisation process to try to find a way of redesigning the interface and facilitating interaction between young people, or any citizen for that matter, and the tax system.

Finally, we recently helped five Danish ministries understand what it would feel like to be an immigrant worker entering the country hoping for work. In this case we chose, amongst others, a highly qualified Indian engineer who arrived in Denmark and tried to find a job, start a new life and manage a family in an unfamiliar country. We started by interviewing eight to 10 individuals in similar circumstances to help share their experiences since their arrival in Denmark, and especially with the Danish public services. Their stories were of disempowerment, being passed from agency to agency, unable to comprehend the systems, often being left waiting, and suffering language problems. The experience for the immigrant family was not discernible to the five ministries individually, but we managed to get a common understanding across to these agencies of what might need to be improved for such new residents.

\section{Design-inspired processes, visualisation and mapping}

You may well be asking yourself: if we are just asking citizens what they want, they will simply want more from us. Also, if we are using qualitative inputs, it is not genuinely representative to just interview six, eight or 10 people. And, of course, it isn't. But there is enormous value in going deeper with a limited number of sources and obtaining concrete information about their experiences. It turns out that if we interview eight or 10 people, or even fewer, about a certain service experience, similar patterns emerge very quickly. And, even though the interviewees may be of different gender, age, and come from different locations, we often find surprisingly coherent patterns of experience that can then drive policy and service design. Hence, I would argue that it's not about being quantitative and statistically representative, rather, it's about harvesting insights that can drive ideation and creation, which is the third component of what I refer to as co-creation.

So far, I have discussed citizen involvement, using expertise and knowledge and gaining inspiration, and about understanding the qualitative experience - but what about creation and the creative process? This is a different kind of process, 
which might be called 'rehearsing the future' - a term coined by the Danmarks Designskole (Danish Design School) in Copenhagen. It involves using a designinspired process to drive the creation of policy and service.

There are two dimensions of design as a practice. The first is design as a product-related discipline, establishing or following the conventions when we are styling fashion or new cars, using graphic design, or designing gadgets or mobile phones. The second dimension of design is far broader in scope than the first and it consists of creating desirable futures. So, designing becomes the practice of creating new futures, and that can involve public services, and it can certainly be applied to systems, organisations and strategies.

To adopt the second meaning of design requires a new set of attitudes and a way of seeing the world, which is not only analytical (something governments are usually good at), but it also emphasises the value of synthesis, looks more holistically at solutions, and looks at what works for people. My argument is that to do this we need to put things together, to apply the mindset of synthesis and develop coherent, meaningful services for people. We need to think about prototyping ideas and innovations — thinking through doing — getting practical and concrete about things. We need to be serious about design not just as an attitude or approach to the world but as a creative process of design action.

Design action is about challenging assumptions - something we rarely do well as public servants. We often take for granted the overall policy framework, or the suggestions we receive from ministers or parliament. And we should be loyal servants, but being a loyal servant can also be about questioning underlying assumptions and, sometimes, about helping reframe what the true problem is. As I mentioned earlier, by getting close to citizens, it is sometimes possible to reframe the fundamental problem. For instance, in the case of the injured workers, the problem was not how do we run an efficient case management process, rather, the problem was that we were making the administrative process meaningless to people; we were making them sicker than they already were, and we were not helping them return to the labour market, and get their lives back on track.

The best designers are certainly concerned with how real people - customers, citizens, users, or whatever - engage with solutions, services, products, artefacts, and systems. In designing policy or services, it is necessary to have the human dimension foremost. We have to understand what drives behaviour and what behaviours are apparent or likely to emerge, what drives motivation and, ultimately, what drives outcomes. That is, in many ways, a fundamental design discipline. 
Experimental design and prototyping are ways of testing out solutions, not as pilots to gauge risk, but as very early first drafts that are even built to fail. We may use prototypes consciously to fail, to learn rapidly, and then intuitively try something different, and then move forward. Because it's an experimental process, however, it requires public servants to be willing to create and test rough drafts. Citizens need to be given the opportunity to say what works in a particular context. This is the tougher creative challenge; we are just trying stuff out to see what works. And that is what we need to do if we want to get policy and services right.

Finally, using visual tools to enable conversations with citizens is also a useful way of obtaining concrete insight into the experiences of citizens. One exercise that we have tried is getting high school students to engage in a conversation about their understanding of money matters, personal finances and tax issues. We wanted a dialogue, so we used a visual tool like a target to help the students prioritise what was most important to them, to assemble all the ideas that we had generated with them into some structure, and into a rough prioritisation.

Visual tools, graphic design and other design tools can help keep the conversation more concrete, more specific, and more tangible about what is needed. At times, we also use role playing exercises and, in this case, we worked with several agencies to conduct a small-scale role playing exercise to negotiate financial transactions and show who might be involved in the service design processes. We gave participants an idea of what a new policy would look and feel like for each of the various actors involved. That is really what designing services can be about - making them visual and concrete.

From the citizen's perspective, we can also use 'service journey mapping' as a way of visualising the pathway of the citizen through the system by capturing all the different interactions they are likely to encounter. So, for instance, an injured Danish worker may experience 'points of pain' in the system at which the system makes no sense to him/her, and this leads to confusion and frustration. And, given the bulk of correspondence some of these individuals have received from the agency, their frustration is not as a result of being uninformed. The problem is that they are probably over-informed and the system and its language does not make sense.

Service journey mapping is a way of visualising services from the vantage point of the citizens, and then using these maps as a driver of common understanding when, for example, various public agencies need to coordinate or collaborate to improve service quality. Agencies can use such mappings to assess what resources there are across the delivery chain, to re-evaluate resource deployment to improve experiences and to consider which can be used more effectively to 
Putting Citizens First

co-produce a new service scenario. The capacity to have such a citizen-centric overview of the system level is critical in assessing the potential for processes of co-creation and system redesign.

\section{Conclusion: Citizens as experts in their own lives}

Using design as a driver in innovation in government is not something that only MindLab is doing. In Australia, the Australian Centre for Social Innovation is using design approaches in its efforts in Adelaide, South Australia. In Finland, the Helsinki Design Lab is working with government officials to bring design - and 'strategic design', as they call it - into government. In France, the socalled 27th Region works with the French regions to redesign regional policies. And, in the United Kingdom, there are a number of consultancies and not-forprofit organisations that are working with design approaches to help craft new government services.

So, the emphasis on design is not something that is novel to Denmark. We are seeing it grow as a discipline and being applied in new ways in social services and in policy. Maybe what we are witnessing in many parts of the globe is the beginning of design being used as a major approach or tool in crafting policies.

Naturally, other tricky issues are raised when we adopt these design principles, such as those concerning relative resourcing, whom to consult, and managing heightened expectations once the design process is underway. From my experience, most people understand that they are not in the process to make decisions, but that they are involved to help qualify decisions that will be made by others who can bring other considerations to bear on the issues. The key point about citizen engagement is that we involve citizens, like the injured workers or the students mentioned earlier, to interrogate them as experts in what they are experts in, which is their own lives. That is the key reason for the sort of co-design or co-creative approaches we are advocating.

To conclude, the three principles of co-creation I have stressed are: getting closeup to citizens and end users, and understanding their concrete experiences; 'zooming out' to the system level to understand what better outcomes we can co-create and how we can deliver them; and, shifting our narrow thinking about service delivery to thinking synoptically about what are the entire set or resources - citizen resources, businesses, and others in society, which can be better utilised to help create better outcomes.

The management challenge today is to recognise that these insights about how citizens experience services can be very powerful, and will need to be accepted by public organisations. The tough part now will be to accept the organisational 
consequences and the necessary changes to systems, processes, behaviours, and attitudes within the system so as to accommodate the insights and the new solutions we discover. That is the challenge - the change management task. I might even go so far as to say that it calls for change leadership. But that's a different story. 